\title{
Thoracic Aortic Aneurysms in Octogenarians: The Results of Open Surgical Repair Using Hypothermic Circulatory Arrest with Antegrade Selective Cerebral Perfusion
}

\author{
Ryuzo Bessho, Yôsuke Ishii, Dai Nishina and Yasuhiro Kawase \\ Department of Cardiothoracic Surgery, Nippon Medical School Chiba Hokusoh Hospital
}

\begin{abstract}
Objective: Although recent progress has expanded the indications for thoracic aortic surgery to include elderly patients, the procedure remains extremely invasive. We performed a chart review to determine the early and late outcomes of thoracic aortic surgery using hypothermic circulatory arrest (HCA) and antegrade selective cerebral perfusion (ASCP) in octogenarians.

Materials and Methods: Of 79 patients who underwent surgery for thoracic aortic aneurysms from April 2007 through December 2012, 8 patients 80 years or older were selected for analysis. Mean age at the time of surgery was $84.3 \pm 1.39$ years. The diagnoses were aortic dissection in 5 patients and degenerative thoracic aneurysm in 3 patients. All patients underwent surgery with HCA. The lowest body temperature was $25^{\circ} \mathrm{C}$. ASCP was used as an additional brain-protection technique. Emergency operations were performed in 5 patients (62.5\%).

Results: The mean duration of HCA was $60.4 \pm 19.7$ minutes, that of aortic cross-clamping time was $143.0 \pm 30.4$ minutes, and mean pump time was $207.8 \pm 44.4$ minutes. The hospital mortality rate was $0 \%$. Major postoperative complications occurred in 3 (37.5\%) patients: stroke, temporary neurologic dysfunction, and paraparesis in 1 patient each. No patients required temporary dialysis for new-onset renal dysfunction. There were no deaths during the 65-month follow-up period.

Conclusion: The early and late outcomes after thoracic aortic surgery at our hospital using HCA with ASCP in octogenarians are acceptable. The operations are performed with an acceptable operative risk, even under emergency situations, including acute aortic dissection. (J Nippon Med Sch 2014; 81: 12-18)
\end{abstract}

Key words: thoracic aortic aneurysm, hypothermic circulatory arrest, antegrade selective cerebral perfusion, octogenarian

Correspondence to Ryuzo Bessho, MD, PhD, Department of Cardiothoracic Surgery, Nippon Medical School Chiba Hokusoh Hospital, 1715 Kamagari, Inzai, Chiba 270-1694, Japan

E-mail: r-bessho@nms.ac.jp

Journal Website (http://www.nms.ac.jp/jnms/) 


\section{Introduction}

Recent advances in surgical techniques and perioperative care in cardiovascular surgery have greatly reduced mortality and morbidity. As a result of advances in surgical techniques, myocardial protection, anesthesia, and critical care, marked and sustained improvements in the early and late outcomes of coronary artery and valvular surgery have been achieved in octogenarians ${ }^{1,2}$. However, repair of thoracic aortic aneurysm is still riskier than other cardiovascular procedures, especially if performed emergently ${ }^{3}$. The continuing debate about whether ascending and aortic arch surgery that requires hypothermic circulatory arrest (HCA) should be performed for octogenarians led to the present study, which analyzed the early and late outcomes of thoracic aortic surgery with HCA in octogenarians ${ }^{4,5}$.

\section{Subject and Methods}

From April 2007 through December 2012, 79 patients underwent thoracic aortic surgery at Nippon Medical School Chiba-Hokusoh Hospital. Eight patients ( 4 men and 4 women) were 80 years or older (mean age, $84.3 \pm 1.39$ years; age range, 82 to 87 years). The reason for repair was aneurysm in 3 cases (37.5\%) and aortic dissection in 5 cases $(62.5 \%$; acute dissection in 4 cases [50\%] and chronic dissection in 1 case [13\%]). All 4 patients with acute dissection had preoperative shock caused by massive hemopericardium and cardiac tamponade. Of the 3 patients with degenerative aneurysms, 1 underwent preoperative resuscitation because of a ruptured aneurysm. Other perioperative patient characteristics are shown in Table 1. The site of aortic disease was the ascending aorta in 3 patients and the aortic arch (including the distal arch) in 5 patients. This study was approved by the Ethics Committee of this hospital.

\section{Operative Techniques}

All operative maneuvers were performed via a median sternotomy. A short left hemicollar incision was also made to improve exposure of the branches of the aortic arch.

The axillary artery and femoral artery were used as sites of cannulation for cardiopulmonary bypass. The right axillary artery was used in all cases, and the left axillary artery was additionally used in 6 cases. The patients were cooled until the rectal or bladder temperature reached $25^{\circ} \mathrm{C}$. Reperfusion and rewarming were always performed in an antegrade fashion via the side branch of the graft. Collagencoated woven Dacron prostheses were used as aortic grafts. One branched graft was used for hemiarch replacement, and a quadrifurcation was used for total arch replacement. If total arch replacement was performed, the arch vessels were independently reconstructed with a quadrifurcated graft without an en bloc repair technique.

Open distal anastomosis was performed in all cases. In 6 of 8 cases, the anastomosis was performed with complete transection of the

Table 1 Preoperative patients' characteristics

\begin{tabular}{|c|c|c|c|c|c|}
\hline Case & Sex & $\begin{array}{c}\text { Age } \\
\text { (years) }\end{array}$ & Diagnosis & Clinical presentation & $\begin{array}{l}\text { Operative } \\
\text { status }\end{array}$ \\
\hline 1 & $\mathrm{~F}$ & 85 & Distal arch-descending thoracic aneurysm & $\begin{array}{c}\text { Abnormal shadow on chest } \\
\text { X-ray film }\end{array}$ & Elective \\
\hline 2 & $\mathrm{~F}$ & 84 & Acute type A aortic dissection & Chest and back pain, shock & Emergency \\
\hline 3 & $\mathrm{~F}$ & 84 & $\begin{array}{c}\text { Chronic type A aortic dissection+ } \\
\text { aortic regurgitation }\end{array}$ & $\begin{array}{l}\text { Congestive heart failure, } \\
\text { dyspnea on exertion }\end{array}$ & Elective \\
\hline 4 & $\mathrm{~F}$ & 83 & Acute type A aortic dissection & Shock & Emergency \\
\hline 5 & M & 82 & Acute type A aortic dissection & Chest and back pain, shock & Emergency \\
\hline 6 & M & 84 & Acute type A aortic dissection & Loss of consciousness, shock & Emergency \\
\hline 7 & M & 87 & Ruptured distal arch thoracic aneurysm & Shock & Emergency \\
\hline 8 & M & 85 & Distal arch-descending thoracic aneurysm & Hoarseness & Elective \\
\hline
\end{tabular}

M, male; F, female 
descending aorta distal to the left subclavian artery for total arch replacement and with complete transection of the aortic arch for hemiarch replacement. The stepwise technique was used for distal anastomosis in cases requiring total arch replacement.

In 2 of 8 cases, the aortic arch was completely transected between the right brachiocephalic artery and the left carotid artery. A stent graft, constructed from a $30 \times 50-\mathrm{mm}$ self-expandable Gianturco Z-shape stent with its distal part covered by a collagen-coated woven Dacron graft, was delivered into the descending aorta with our originally developed delivery forceps, with the distal end about $6 \mathrm{~cm}$ below the aneurysm, under monitoring with transesophageal echocardiography and an endoscope in the aorta.

Antegrade selective cerebral perfusion (ASCP) was performed with bilateral axillary artery cannulation using an 8- or 10-mm collagen woven Dacron tube graft, sutured to the axillary artery in an end-to-side fashion, and with a balloon-tipped cannula inserted directly into the left common carotid artery from inside the aortic arch. The ASCP was started at the rate of $10 \mathrm{~mL} \cdot \mathrm{kg}^{-1} \cdot \mathrm{min}^{-1}$ separate from the systemic circulation. Two separate arterial lines from the pump oxgenator were used for the right and left cerebral perfusions during open distal anastomosis, and a $1: 1$ ratio of flow through the 2 arterial lines was achieved during the operation through the use of in-line flowmeters.

\section{Concomitant Procedures}

Concomitant procedures included aortic valve resuspension for acute dissection in 3 patients and aortic valve replacement, composite graft replacement with coronary reimplantation, and coronary artery bypass grafting in 1 patient each.

\section{Follow-up}

The patients were followed up until January 2013 at the outpatient clinic or by telephone. The rate of follow-up was $100 \%$. The mean duration of clinical follow-up was $34.2 \pm 16.7$ months with a maximum of 65 months.

\section{Outcomes and Statistical Analysis}

Data were analyzed with the software package IBM SPSS Statistics Version 21.0 (IBM Corp., Armonk, NY, USA). Standard descriptive statistical analyses were used. Continuous data are presented as mean \pm standard deviation or standard error. Nonparametric estimates of freedom from all-cause death and readmission were determined with the Kaplan-Meier method. Statistical analysis of the time course of the estimated glomerular filtration rate (eGFR) and serial amylase levels was performed with one-way repeated-measures analysis of variance (ANOVA), and if any statistical significance was observed, the Bonferroni multiple comparison test was applied. The e-GFR $\left(\mathrm{mL} / \mathrm{min} / 1.73 \mathrm{~m}^{2}\right)$ was calculated with the following equation: $194 \times$ serum creatinine $(\mathrm{mg} / \mathrm{dL})^{-1.094} \times$ age $\quad(\text { year })^{-0.287} \times 0.739 \quad$ (if female). Differences were considered statistically significant at $p<0.05$. In-hospital mortality was defined as any death occurring during the postoperative hospital stay, regardless of the time elapsed since the operation. Thirty-day mortality was defined as any death within 30 days of surgery, even if it occurred after hospital discharge. Postoperative stroke was defined as a newly developing neurologic deficit confirmed with computed tomography. Temporary neurologic dysfunction (TND) was defined as postoperative confusion, agitation, or delirium with negative findings on computed tomography of the brain and complete resolution before discharge.

\section{Results}

Operative details are shown in Table 2. The mean duration of hypothermic circulatory arrest was $60.4 \pm$ 19.7 minutes, that of aortic cross-clamping was $143.0 \pm 30.4$ minutes, and mean pump time was $207.8 \pm$ 44.4 minutes.

Postoperative clinical outcomes are summarized in Table 3. Total hospital mortality was zero (0\%). Stroke occurred in 1 patient. An 84-year-old man had acute type A dissection with loss of consciousness and shock before surgery. Computed tomography of the brain before surgery and 14 days after surgery revealed no focal ischemia but did 
Thoracic Aortic Aneurysm in Octogenarians

Table 2 Operative details

\begin{tabular}{|c|c|c|c|c|c|}
\hline Case & Operative procedure & Arterial cannulation & $\begin{array}{c}\text { Duration of } \\
\text { HCA } \\
\text { (minutes) }\end{array}$ & $\begin{array}{l}\text { Cross-clamp } \\
\text { duration } \\
\text { (minutes) }\end{array}$ & $\begin{array}{l}\text { Bypass } \\
\text { duration } \\
\text { (minutes) }\end{array}$ \\
\hline 1 & $\begin{array}{l}\text { Distal arch-discending replacement } \\
\text { with frozen elephant trunk }\end{array}$ & Bil. axillary+femoral & 74 & 141 & 183 \\
\hline 2 & Hemiarch replacement & Rt. axillary+femoral & 57 & 110 & 187 \\
\hline 3 & $\begin{array}{c}\text { Total arch replacement and aortic } \\
\text { valve replacement }\end{array}$ & Bil. axillary+femoral & 41 & 173 & 223 \\
\hline 4 & $\begin{array}{c}\text { Hemiarch, composite graft } \\
\text { replacement and coronary artery } \\
\text { bypass grafting }\end{array}$ & Rt. axillary+femoral & 39 & 201 & 315 \\
\hline 5 & Hemiarch replacement & Bil. axillary+femoral & 55 & 118 & 174 \\
\hline 6 & Hemiarch replacement & Bil. axillary+femoral & 49 & 116 & 182 \\
\hline 7 & $\begin{array}{l}\text { Distal arch-discending replacement } \\
\text { with frozen elephant trunk }\end{array}$ & Bil. axillary+femoral & 104 & 161 & 222 \\
\hline 8 & Total arch replacement & Bil. axillary+femoral & 64 & 124 & 176 \\
\hline
\end{tabular}

HCA, hypothermic circulatory arrest

Table 3 Clinical outcomes

\begin{tabular}{cccccc}
\hline Case & Postoperative complications & $\begin{array}{c}\text { Intubation } \\
\text { time } \\
\text { (hour) }\end{array}$ & $\begin{array}{c}\text { intensive } \\
\text { care unit stay } \\
\text { (days) }\end{array}$ & $\begin{array}{c}\text { Duration of } \\
\text { hospitalization } \\
\text { (days) }\end{array}$ & Outcomes \\
\hline 1 & Temporary neurologic dysfunction & 43 & 9 & 22 & Alive now \\
2 & none & 18 & 5 & 17 & Alive now \\
3 & none & 9 & 15 & 33 & Alive now \\
4 & none & 35 & 4 & 25 & Alive now \\
5 & none & 26 & 4 & 20 & Alive now \\
6 & Stroke, Pneumonia $\rightarrow$ tracheotomy & 965 & 25 & 131 & Alive now \\
7 & Paraparesis & 358 & 18 & 55 & Alive now \\
8 & none & 11 & 5 & 23 & Alive now \\
\hline
\end{tabular}

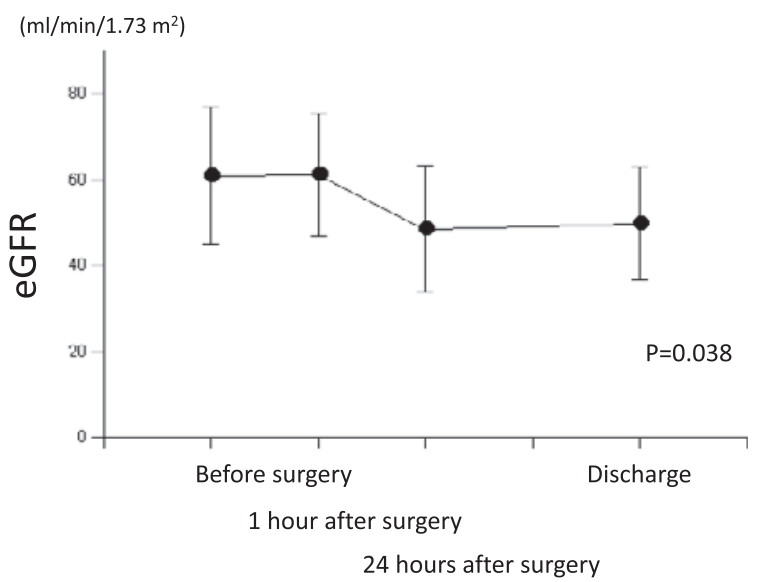

Fig. 1 Changes in eGFR during the perioperative period

Data points represent mean; error bars represent SD.

show evidence of a left-sided infarct outside the putamen 50 days after surgery. Paraparesis due to a spinal cord ischemic injury developed in 1 patient. An 87-year-old man underwent emergent frozen elephant trunk surgery for a ruptured aneurysm of the distal thoracic aortic arch. With rehabilitation, lower extremity strength improved in this patient. TND occurred in 1 patient but resolved completely.

No patients required temporary dialysis for newonset renal dysfunction. Figure $\mathbf{1}$ shows changes in eGFR before and after surgery. There were significant differences in eGFR during hospitalization $(\mathrm{p}=0.038)$.

Figure 2 shows the postoperative survival curve. During the follow-up period, which extended to 65 months, there were no deaths. All patients are currently alive. Two patients were readmitted for pneumonia and acute pancreatitis 23 months and 16 months after discharge. Both patients recovered, owing to medical treatment, within several weeks. 


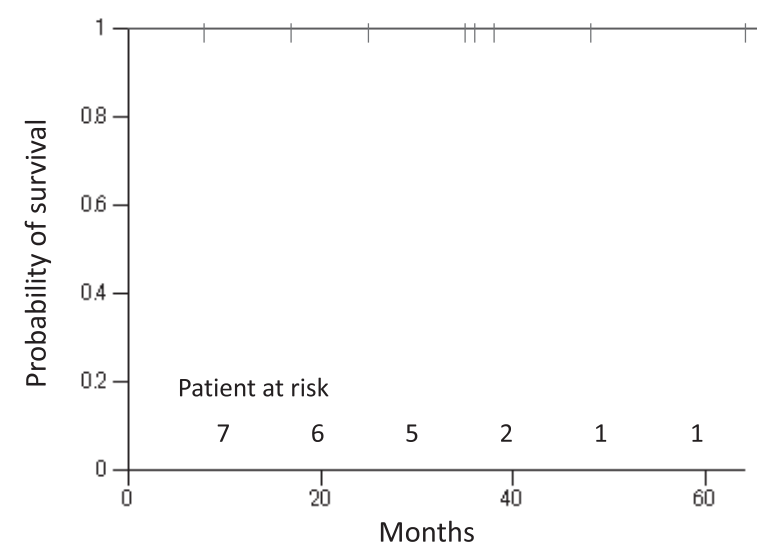

Fig. 2 Postoperative survival curve in octogenarians with thoracic aortic aneurysm

The 5-year rate of freedom from all-cause readmission was $68.6 \%$ (Fig. 3).

\section{Discussion}

Owing to the increasing number of octogenarians in the Japanese population, the number of elderly patients referred for surgery for cardiovascular diseases has been increasingly steadily ${ }^{6}$. Octogenarians who undergo cardiac surgery have higher rates of comorbidity and mortality. Age alone has been shown to affect outcomes after cardiovascular surgery. Several studies have shown that older patients have considerably higher rates of postoperative stroke and mortality and longer hospitalizations ${ }^{3.6 .7}$. Owing to advances in perioperative care, anesthesia management, and brain and myocardial protection during surgery, and advances in surgical technique, the outcomes of coronary bypass, valvular heart disease, and abdominal aortic aneurysm surgeries are acceptable in octogenarians ${ }^{1,2,9}$. However, thoracic aortic surgery, which requires HCA, remains an extremely invasive procedure. Prolonged cardiopulmonary bypass and profound HCA have been implicated in early morbidity and mortality, and several studies have found ${ }^{45,10,11}$ considerably higher rates of postoperative stroke and mortality and prolonged hospital stays.

Hospital mortality rates in previous studies $^{3-5,12,13}$ have ranged from $7.9 \%$ to $83.3 \%$. Neurologic complications comprise permanent stroke in $3 \%$ to

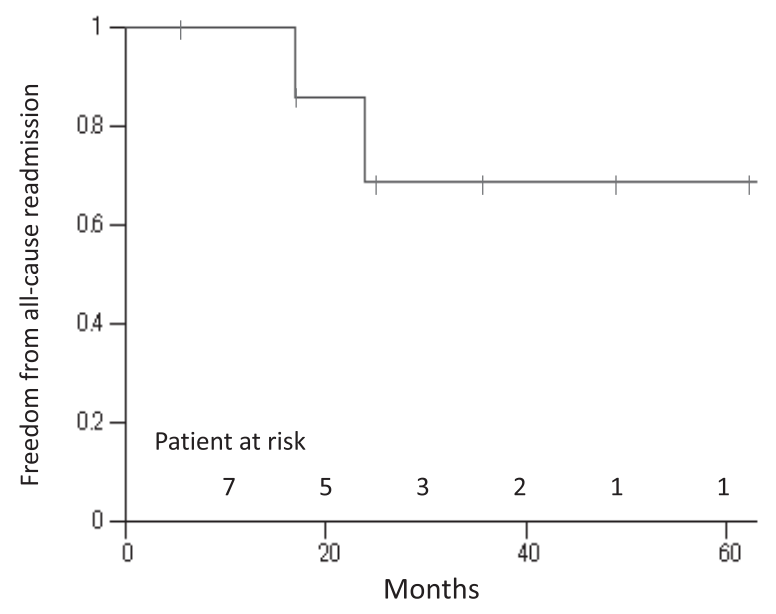

Fig. 3 Freedom from all-cause readmission in octogenarians with thoracic aortic aneurysm

$54.2 \%$ of patients and TND in $5.3 \%$ to $73 \%$ of patients. The rates of mortality and morbidity are even higher among elderly patients. In our present study of octogenarians undergoing surgery with HCA to repair thoracic aortic aneurysms the overall in-hospital mortality rate of $0 \%$, which compares favorably with mortality rates in similar studies. Even in our patients who underwent emergency operations for acute aortic dissection or ruptured aneurysm, there was no hospital mortality. The neurological complications in the present study were permanent stroke, TND, and paraparesis in 1 patient each (each 12.5\%). All 3 cases were emergent. Therefore, surgical repair of thoracic aortic aneurysms with HCA appears acceptable in this group of patients, even though they are a high-risk group. If all 79 our patients, both patients 80 years or older and patients younger than 80 years (mean age, 66.4 years), who underwent surgery during the study period at our institution are included, the hospital mortality rate was $7.6 \%$ (6 of 79 patients)and the rate of neurological complications was $6.3 \%$ (5 of 79 patients).

The incidence of neurologic complications, most often permanent stroke and TND, is high after operations in which HCA is used. Risk factors for permanent neurologic deficit include type A aortic dissection, age, duration of circulatory arrest, and total arch replacement. Three methods of brain protection have been used since 1975: HCA as a basic method, either alone or with ASCP, or 
retrograde cerebral perfusion $(\mathrm{RCP})$ as an adjunctive method. Extensive research ${ }^{14-21}$ regarding the controversies surrounding the ideal form of cerebral protection clearly indicate that ASCP is superior to $\mathrm{RCP}$ for brain protection. Many researchers ${ }^{14-22}$ have shown that the use of RCP fails to decrease the incidence of TND. We have consistently used ASCP from our first case of patients to ensure brain protection.

Acute kidney injury is a serious complication that can occur after cardiac surgery ${ }^{23-25}$. Acute kidney injury has come to be defined as the composite outcome of acute kidney injury requiring dialysis or a $50 \%$ or greater decrease in postoperative GFR relative to baseline but not requiring dialysis. On the other hand, GFR as calculated according to the clearance of exogenous markers, such as insulin, is more accurate, but the procedure is lengthy. As an alternative, e-GFR equations have been recommended for use in clinical practice. Equations based on standardized serum creatinine, such as the Modification of Diet in Renal Disease Study ${ }^{26}$ equation, have been used most commonly worldwide. We therefore used e-GFR, as modified for Japanese patients by Imai et al., ${ }^{27.28}$ to investigate renal function during the perioperative period. The renal function of our present patients decreased significantly after surgery, but no patients required dialysis or showed a decrease in e-GFR greater than $50 \%$ of the basal value, which suggests that HCA, which involves reducing systemic temperature to around $25^{\circ} \mathrm{C}$ for up to 60 minutes, does not lead to severe or acute kidney injury.

The percentage of operations in this study that were performed on an emergent basis was greater than $60 \%$. Elderly patients are often referred late in the course of a disease. Although the clinical outcome for elective surgery in octogenarians is satisfactory, in emergency cases the rates of morbidity and mortality are markedly increased. Acute aortic dissection is difficult to prevent, but asymptomatic aortic aneurysms in octogenarians might be recognized and treated at an early stage. Our indications for elective thoracic aortic surgery in octogenarians are essentially the same as for younger patients. If patients are still enjoying active lives, we believe that age is not an absolute contraindication for thoracic aortic surgery.

A limitation of the present study was the small number of cases, and we were not able to further analyze risk factors for postoperative neurologic complications or other major complications. This study provided data on the surgical outcomes of thoracic aortic surgery in octogenarians at Nippon Medical School's Chiba-Hokusoh Hospital. The surgical outcome of very elderly patients is a good indicator of the overall quality of a hospital, because the treatment and care of very elderly patients are more problematic than those of younger patients, and aortic arch surgery remains one of the most invasive procedures in cardiovascular surgery.

In conclusion, the early and late outcomes after thoracic aortic surgery using HCA with ASCP in octogenarians at our hospital are acceptable. The operations are performed with an acceptable operative risk, even under emergency situations that include acute aortic dissection.

Conflict of Interest: No author has any conflict of interest.

\section{References}

1. Speziale G, Nasso G, Barattoni MC, et al.: Short-term and long-term results of cardial surgery in elderly and very elderly patients. J Thorac Cardiovasc Surg 2011; 141: 725-731.

2. Krane M, Voss B, Hiebinger A, et al.: Twenty years of cardiac surgery in patients aged 80 years and older: Risk and benefits. Ann Thorac Surg 2011; 91: 506-513.

3. Neri E, Toscano T, Massetti M, et al.: Operation for acute type A aortic dissection in octogenarians: is it justified? J Thorac Cardiovasc Surg 2001; 121: 25267.

4. Liddicoat JR, Redmond JM, Vassieva CM, Baumgarter WA, Cameron DE: Hypothermic circulatory arrest in octogenarians: risk of stroke and mortality. Ann Thorac Surg 2000; 69: 1048-1051.

5. Hagl C, Galla JD, Spielvogel D, et al.: Is aortic surgery using hypothermic circulatory arrest in octogenarians justifiable? Euro J Cardiothorac Surg 2001; 19: 417-422.

6. Shah PJ, Estrera AL, Miller CC III, et al.: Analysis of ascending and transverse aortic arch repair in octogenarians. Ann Thorac Surg 2008; 86: 774-779.

7. Avery GJ 2nd, Ley SJ, Hill JD, et al.: Cardic surgery in the octogenarian: evaluation of risk, cost, and outcome. Ann Thorac Surg 2001; 71: 591-596.

8. Alexander KP, Anstrom KJ, Muhlbaier LH, et al: 
Outcomes of cardiac surgery in patients $>$ or $=80$ years: results from the National Cardiovascular Network. J Am Coll Cardiol 2000; 35: 731-738.

9. Woo EY, Ullery BW, Carpenter JP, et al.: Open abdominal aortic aneurysm repair is feasible and can be done with excellent results in octogenarians. J Vasc Surg 2011; 53: 278-284.

10. Chiappini B, Tan ME, Morshuis W, et al.: Surgery for acute type A aortic dissection: is advanced age a contraindication? Ann Thorac Surg 2004; 78: 585590

11. Kawahito K, Adachi H, Yamaguchi A, Ino T: Early and late surgical outcomes of acute type A aortic dissection in patients aged 75 years and older. Ann Thorac Surg 2000; 70: 1455-1459.

12. Augoustides JG, Pochettino A, Ochroch EA, et al.: Clinical predictors for prolonged intensive care unit stay in adults undergoing thoracic aortic surgery requiring deep hypothermic circulatory arrest. J Cardiothorac Vasc Anesth 2006; 20: 8-13.

13. Shiono M, Hata M, Sezai A, et al.: Emergency surgery for acute type A aortic dissection in octogenarians. Ann Thorac Surg 2006; 82: 554-559.

14. Usui A, Yasuura $\mathrm{K}$, Watanabe $\mathrm{T}$, Maseki $\mathrm{T}$ : Comparative clinical study between retrograde cerebral perfusion and selective cerebral perfusion in surgery for acute type A aortic dissection. Euro J Cardiothorac Surg 1999; 15: 571-578.

15. Coselli J: Retrograde cerebral perfusion is an effective means if neural support during deep hypothermic circulatory arrest. Ann Thorac Surg 1997; 64: 908-912.

16. Kazui T, Yamashita K, Washiyama N, et al: Usefulness of antegrade cerebral perfusion during aortic arch operations. Ann Thorac Surg 2002; 74: S1806-S1809.

17. Di Eusanio M, Schepens M, Morquis W, et al.: Brain protection using antegrade selective cerebral perfusion: a multicenter study. Ann Thorac Surg 2003; 76: 1181-1189.

18. Svensson L, Crawford E, Hes E, et al.: Deep hypothermia with circulatory arrest: determinants of stroke and early mortality in 656 patients. J Thorac Cardiovasc Surg 1993; 106: 19-31.

19. Ergin M, Uysal S, Reich D, et al.: Temporary neurological dysfunction after deep hypothermic circulatory arrest: a clinical maker of long-term functional deficit. Ann Thorac Surg 1999; 67: 18871890.

20. Griepp R: Cerebral protection during aortic arch surgery. J Thorac Cardiovasc Surg 2001; 121: 425427.

21. Harrington D, Walker A, Kaukunta H, et al: Selective antegrade cerebral perfusion attenuates brain metabolic deficit in aortic arch surgery. Circulation 2004; 110(Suppl. 1): II231-II236.

22. Apostolakis E, Shuhaiber JH: Antegrade or retrograde cerebral perfusion as an adjunct during hypothermic circulatory arrest for aortic arch surgery. Expert Rev Cardiovasc Ther 2007; 5: 11471161.

23. Thakar CV, Worley S, Arrigain S, Yared J-P, Paganini EP: Influence of renal dysfunction on mortarity after cardiac surgery: Modifying effect of preoperative renal dysfunction. Kidney Int 2005; 67: 1112-1119.

24. Chertow GM, Levy EM, Hammermeister KE, Grover F, Daley J: Independent association between acute renal failure and mortality following cardiac surgery. Am J Med 1998; 104: 343-348.

25. Thakar CV, Worley S, Arrigain S, Yared J-P, Paganini EP: Improved survival in acute kidney injury after cardiac surgery. Am J Kidney Dis 2007; 50: 703-711.

26. Levey AS, Coresh J, Greene T, et al.: Using standerd serum creatinine values in the modification of diet in renal disease study equation for estimating glomerular filtration rate. Ann Intern Med 2006; 145: 247-254.

27. Imai $E$, Horio $M$, Nitta $K$, et al:: Estimation of glomerular filtration rate by MDRD study equation modified for Japanese patients with chronic kidney disease. Clin Exp Nephrol 2007; 11: 41-50.

28. Horio M, Imai E, Yasuda Y, et al.: Modification of the CKD epidemiology collaboration (CKD-EPI) equation for Japanese Accuracy and use for poplation estimates. Am J Kidney Dis 2010; 56: 32-38.

(Received, March 6, 2013)

(Accepted, June 7, 2013) 